\title{
Characterization of the Effect of Melt Treatments on Melt Quality in Al-7wt \%Si-Mg Alloys
}

\author{
Muhammet Uludağ ${ }^{1}$, Remzi Çetin ${ }^{2}$, Derya Dispinar ${ }^{3}$ and Murat Tiryakioğlu ${ }^{4, *}$ \\ 1 Department of Metallurgical and Materials Engineering, Faculty of Natural Sciences, \\ Architecture and Engineering, Bursa Technical University, Bursa, Turkey; dr.uludagm@gmail.com \\ 2 Faculty of Engineering, Halic University, Istanbul, Turkey; remzicetin042@gmail.com \\ 3 Faculty of Engineering, Istanbul University, Istanbul, Turkey; deryad@istanbul.edu.tr \\ 4 School of Engineering, University of North Florida, Jacksonville, FL 32224, USA \\ * Correspondence: m.tiryakioglu@unf.edu; Tel.: +1-904-620-1390; Fax: +1-904-620-1391 \\ Academic Editor: Nong Gao \\ Received: 22 February 2017; Accepted: 27 April 2017; Published: 29 April 2017
}

\begin{abstract}
The effects of degassing, holding time and melt additions $(\mathrm{Sr}, \mathrm{Sr}+\mathrm{Ti}, \mathrm{Ti}, \mathrm{B}$ and $\mathrm{B}+\mathrm{Sr}$ ) on the quality of A356 melts were examined. A total of 120 reduced pressure test samples were collected. Pores in these samples were analyzed via digital image processing to determine the number density of pores as well as the statistical distribution of their sizes. Results showed that in all cases, degassing with argon reduced the number of defects regardless of the additions made to the melts. Moreover, all additions were found to degrade melt quality. The lowest number density of pores in all melts was achieved in melts with no additions that were degassed. In both degassed and non-degassed melts, Sr additions degraded the melt quality significantly. The mechanisms of melt quality improvement or degradation with different melt treatments are discussed in the paper.
\end{abstract}

Keywords: A356 alloy; degassing; grain refinement; modification; pore size

\section{Introduction}

Cast Al-Si-Mg alloys display a good combination of corrosion resistance and castability, in addition to their high strength to density ratio. Therefore, these alloys are widely used in automotive and aerospace industries, sometimes in critical applications. Hence, it is crucial to produce castings that exhibit high tensile properties and fatigue performance. For production of high quality castings, the initial melt must have a low number of defects, and the filling system of the casting should be designed to prevent any additional damage to the liquid metal [1].

Porosity is a structural defect common in most castings and has been referred to as one of the root causes for deterioration of properties and performance of cast parts. Porosity has been characterized as either gas or shrinkage porosity based on its shape [2]. Round pores are usually assumed to have been formed by nucleation of gas. Therefore, degassing techniques have been used to reduce amount of the dissolved gases in liquid metals, such as $\mathrm{H}$ in molten $\mathrm{Al}$, and thereby reducing the number of round pores. Irregular or tortuous pores have been attributed to negative pressures developed during solidification. To overcome this type of porosity, researchers [3,4] investigated feeding mechanisms in castings and the efficiency of different types of feeders. Moreover, melt treatments such as grain refining and Si eutectic modification have been studied to obtain a microstructure in cast Al-Si alloys to alter the microstructure and minimize the detrimental effect of pores on mechanical properties.

Recently, an alternative explanation to the mechanism of pore formation was provided by Campbell [5] who attributed both type of pores to the presence of oxide films in the bulk of the liquid. These oxide films, named bifilms, are originally surface films that fold over and got entrained into the bulk of liquid metal during melting or as a result of surface turbulence. Subsequently, bifilms 
open up due to the diffusion of gas and/or contraction of the solidifying metal, resulting in pores. Campbell's explanation for pore formation has been validated recently [6-16]. Hence, it has been proposed that bifilms are the underlying reason for pores and the root cause for reduction in properties that have been traditionally attributed to pores.

Although the effects of degassing and melt additions on microstructure and mechanical properties have been investigated extensively, their effect on defect content and their size distribution has not been studied. To bridge this gap, in this study, melt quality of A356 alloy was investigated under twelve different conditions to evaluate the combined effects of grain refinement, modification, degassing and holding time.

\section{Background}

Strontium is added to Al-Si alloys so that the morphology of Si eutectic changes from acicular to fibrous, and consequently mechanical properties are improved [12,17-19]. However, Sr additions have been reported [20] to increase porosity in $\mathrm{Al}$ castings. Some users have even reported that the increased porosity due to $\mathrm{Sr}$ negates any beneficial effects of modification, and consequently they abandoned the use of Sr [21-23].

The interaction between bifilms in the melt and Sr additions in initiating pores has been recently proposed by Campbell [24]. Similar results were found by Iwahori et al. [25] who investigated the effect of $\mathrm{Sr}$ additions on porosity formation in Al-7\%Si alloys. They reported that there was a correlation between the number of oxides in the melt and porosity for Sr modified A356. If the oxide content in the melt was low, Sr additions combined with vacuum degassing did not lead to porosity. When the oxide content was high, Sr addition followed by vacuum degassing did result in increased porosity. Iwahori et al. [25] stated that $\mathrm{Sr}$ additions increased the $\mathrm{H}$ concentration in the melt. When oxides were present, subsequent vacuum degassing was not efficient because $\mathrm{H}$ was strongly fixed in oxides. The results of Iwahori et al. [25] contradict those reported by Gruzleski et al. [26] who found that $\mathrm{H}$ content was not changed after Sr addition to an A356 alloy melt. Argo and Gruzleski [27] investigated the effect of Sr modification on how A356 shrinks during solidification by using the Tatur test. In unmodified alloys, metal created a larger central shrinkage pipe and low level of internal microshrinkage. After $\mathrm{Sr}$ addition, the size of the central pipe got smaller but the internal microshrinkage level increased. Similar results were reported by Dinnis et al. [28] for Al-9\%Si alloy. Tiedje et al. [29,30] investigated the effect of $\mathrm{Sr}$ modification and cooling rate on size and distribution of porosity in Al-7\%Si and Al-12\%Si alloys and observed three different microstructural zones from surface to center in samples. They found that pore area and number of pores per unit area, i.e., number density $(N)$, increased after $\mathrm{Sr}$ addition in all three zones for both alloys. Similar results were reported by Liao et al. [31] who investigated the effect of Sr concentration on the amount of porosity in Al-12.3\%Si alloy. Sr modification increased both number density of pores and volume fraction of porosity. Roy et al. [32] found that Sr additions to melts of an $\mathrm{Al}-9 \% \mathrm{Si}-3 \% \mathrm{Cu}$ alloy increased the number density of pores and distributed them evenly in the casting. Liu et al. [14] conducted research on the effect of Sr content on porosity and the type of oxide formed in RPT samples as a result of Sr addition in A356 and 319 cast aluminum alloys. They confirmed that $\mathrm{Sr}$ additions increased porosity, regardless of the level of $\mathrm{H}$ content. They also determined that $\mathrm{Sr}$ additions result in the formation of $\mathrm{Al}_{2} \mathrm{SrO}_{3}$ spinel oxide, which serve as initiation sites for pores, and that rotary degassing with Ar was essentially ineffective in removing these oxides. These results in the literature show that Sr addition increases the number of bifilms in the melt. These bifilms are probably much finer than the "old" oxides that used to be the skin of the ingot or the remelts. That is why they are efficient in redistributing porosity and making pores finer.

Farhoodi et al. [33] investigated the effect of holding time of the melt on porosity in commercial purity and Sr-containing $\mathrm{Al}$ alloys. In the unmodified alloy, as holding time was increased up to $30 \mathrm{~min}$, total porosity area initially increased, reaching a peak at $30 \mathrm{~min}$, after which it started to decrease. When holding time was $60 \mathrm{~min}$, porosity was reduced to zero. However, in Sr modified alloy, as holding time was increased, total porosity was reduced consistently. At the same time, when $\mathrm{Sr}$ 
concentration decreased from $0.035 \%$ to $0.005 \%$, porosity decreased by almost $80 \%$. Similar results were reported by El-Sayed et al. [34] who studied the number of bifilms in the melt and subsequent tensile properties in Al-7Si-0.3Mg alloy after 0, 10 and 20 min of holding time. Results showed that a hold time of 10 min was optimum to obtain high casting quality for both low and high hydrogen levels. The results are in contrast with those reported by Haberl et al. [35] who found that the number density of pores in reduced pressure test (RPT) samples decreased with holding time up to $50 \mathrm{~min}$.

In Al-Si alloys, Al-Ti-B grain refiners are added to alter the coarse-heterogeneous $\alpha$ - $\mathrm{Al}$ to finer homogeneous dendrites without changing the morphology of eutectic Si [36]. As an alternative to Ti grain refinement, $\mathrm{Al}-3 \mathrm{~B}$ master alloy can also be used which produces $\mathrm{AlB}_{2}$ and $\mathrm{B}$ in the melt to act as heterogeneous nucleation sites for grains [37]. Dispinar et al. [38] investigated the differences in porosity distribution between Ti-B and B grain refinement additions. More localized porosity was observed with B grain refinement compared to the evenly distributed pores with Ti-B grain refinement. The reason for this behavior was addressed independently by Arnberg et al. [39] who studied grain refinement with B in the absence of Ti and observed more globular dendrites with B additions than with Ti additions. The results of these two studies can be interpreted together; bifilms are pushed to the center of the casting when B is added, resulting in porosity being concentrated in the center of castings. Moreover, Dispinar et al. [38] stated that, as it was first uncovered by Schaffer and Dahle [40], Ti tended to sink to the bottom due to higher density which is known as fading. With B grain refinement, due to the eutectic reaction, there was no fading effect, i.e., no sedimentation.

Anyalebechi [41] studied the effects of solidification rate, grain refining by Al-5Ti-0.2B additions and hydrogen concentration on porosity formation in a 2024 alloy. To have different treatments from the same melt, molten metal was transferred from a $45 \mathrm{~kg}$ crucible to a $3 \mathrm{~kg}$ crucible. Results showed that pore size distribution and number density of pores were essentially the same in non-grain refined samples with high hydrogen content and grain refined samples with low hydrogen content. Anyalebechi [41] concluded that Al-5Ti-0.2B additions increased pore sizes and number of pores in 2024 alloy products. Similar results were reported by Fakhraei et al. [42] who studied the effect of Al-5Ti-1B grain refiner on pore sizes in an $\mathrm{Al}-20 \% \mathrm{Mg}$ alloy. They observed that as Ti amount increased in the melt, porosity increased. Lee et al. [43] investigated the effect of melt treatments including modification by Sr addition and grain refinement with Ti as well as degassing on the porosity and tensile properties in A356 alloy castings. They determined that $\mathrm{Sr}$ and Ti additions increased porosity. However, degassing, with or without other melt treatments, significantly decreased porosity and consequently improved tensile properties. Similar results were found by Haberl et al. [35] who reported almost $50 \%$ reduction in number density of pores in RPT samples after degassing. Although it is well known that degassing reduces the hydrogen content, the main contribution of degassing is considered to be the floatation of bifilms to the melt surface $[14,44-46]$.

Although the literature is rich with results on the effect of melt additions, degassing and holding times on melt quality, a comparative study in which most commonly used melt additions, treatments and holding time are tested simultaneously has not been conducted. The present study is intended to fill this gap.

\section{Materials and Methods}

A356 alloy that was used in this study was provided as cast ingots from ETI ALUMINYUM, Turkey. Chemical composition of the alloy is given in Table 1. Ingots were cut to be charged into the crucible. A resistance furnace that has $22 \mathrm{~kg}$ capacity was used to melt the alloy. In non-degassed melts, grain refinement and modification additions were made once the melt temperature had reached $1013 \mathrm{~K}\left(740^{\circ} \mathrm{C}\right)$. Master alloys used in this work were Al-Ti5B1, AlSr15 and Al-3B with the chemical compositions given in Table 2. Al-Ti5-B1 and Al-3B alloys were added into liquid A356 for grain refinement to obtain a concentration $10 \mathrm{ppm} \mathrm{Ti}$ or $10 \mathrm{ppm}$ B. AlSr15 alloy was added the melt for modification to obtain a concentration $30 \mathrm{ppm}$. The experimental design with combination of 
alloying additions is provided in Table 3. Castings and sample collection were started after $10 \mathrm{~min}$ of holding period.

Table 1. Chemical composition (in wt \%) of the A356 alloy used in the study.

\begin{tabular}{ccccccccc}
\hline Alloy & Si & Fe & Cu & Mn & Mg & Zn & Ti & Al \\
\hline A356 & 6.80 & 0.19 & 0.003 & 0.001 & 0.30 & 0.011 & 0.108 & Rem. \\
\hline
\end{tabular}

Table 2. Chemical composition (in wt \%) of the master alloys.

\begin{tabular}{cccccccc}
\hline Master Alloys & Ti & Sr & B & Fe & Si & Ca & Al \\
\hline AlSr15 & - & $14-15$ & - & $\leq 0.2$ & $\leq 0.2$ & $\leq 0.2$ & Rem. \\
AlTi5B1 & 5 & - & 1 & $\leq 0.2$ & $\leq 0.2$ & - & Rem. \\
Al3B & - & - & $2.5-3.5$ & 0.3 & 0.2 & - & Rem. \\
\hline
\end{tabular}

Table 3. The parameters investigated in this work.

\begin{tabular}{cc}
\hline Parameter & Levels \\
\hline Degassing & No degassing; degassing \\
Holding time (min) & 10; 15; 20; 25; 30 \\
Melt additions & AlSr15; AlSr15 + AlTi5B1; AlTi5B1; Al3B; AlSr15 + Al3B \\
\hline
\end{tabular}

For degassing process, a T-type graphite lance was used. Degassing process was started when melt temperature reached $1013 \mathrm{~K}\left(740^{\circ} \mathrm{C}\right)$ and was carried out for $20 \mathrm{~min}$ with argon. Gas flow rate was held at $2 \mathrm{~L} / \mathrm{min}$. Master alloy additions were made when the degassing was completed and after the surface of the melt was skimmed.

A sand mold that can take two samples at same time was used to obtain RPT samples in vacuum of $80 \mathrm{mbar}$ [10]. Samples had rectangular shape with height of $55 \mathrm{~mm}$ and a thickness of $10 \mathrm{~mm}$. RPT was conducted for five different holding times. The first sample was collected in $10 \mathrm{~min}$ after addition of the modifiers. Subsequent samples were collected in $5 \mathrm{~min}$ intervals up to $30 \mathrm{~min}$. To evaluate any possible sedimentation effects, $3 \mathrm{~kg}$ of liquid metal was poured into a separate mold. Consequently, the height of the metal was decreased and the effect of height of liquid alloy in crucible on bifilm index was examined. All RPT samples were cut into two vertically (cross section) and one half was prepared with sandpaper for image analysis. In this process, 60, 180, 400 and 600 grid sandpapers were used in sequence. Subsequently, all RPT samples were scanned with 600 dpi resolution. Digital image analysis was conducted on each specimen by following the guidelines provided by Dispinar and Campbell [47] and using SigmaScan software (Version 4, Systat Software, Inc., San Jose, CA, USA). In total, 120 RPT samples were examined.

\section{Results and Discussion}

The cross sections of RPT samples collected from degassing trials after melt was held for $10 \mathrm{~min}$ are presented in Figures 1-4. Differences between degassed and non-degassed samples can be clearly seen for all conditions. While varying levels of porosity is evident in non-degassed castings, the number of pores is significantly reduced after degassing. This is an indication that rising bubbles during degassing had cleared the bifilms in the melt. It is also clear that some conditions are almost free from pores after degassing, for example: AlTi5B1 and Al3B additions. Among the non-degassed samples, the alloy with no modification has the lowest porosity. The other conditions have higher porosity. Hence, all additions damage the molten metal when the metal is not degassed. This is an evidence of "bifilms created by charging through the surface entrainment" as explained by Campbell [1]. Without degassing, AlSr15 + Al3B addition gives the most damage to the molten metal quality. 


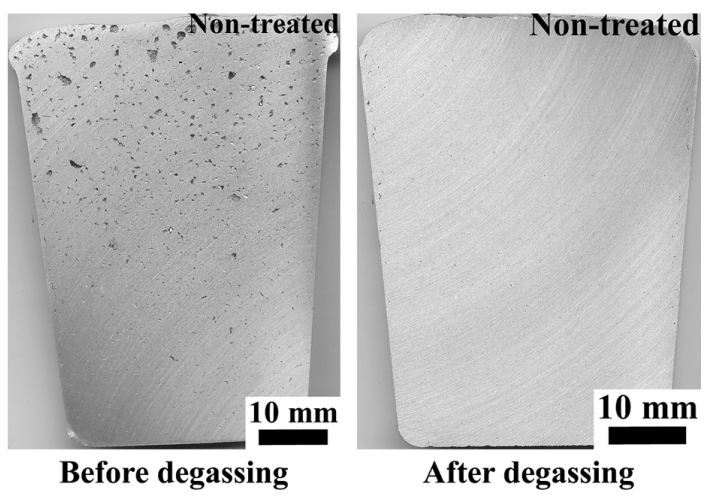

Figure 1. Cross sections of RPT samples for non-treated alloy after $10 \mathrm{~min}$ of holding time.

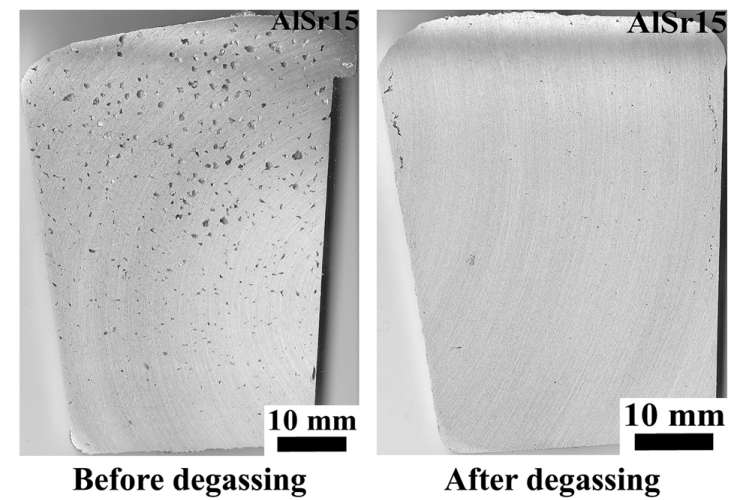

Figure 2. Cross sections of RPT samples for AlSr15 added alloy after $10 \mathrm{~min}$ of holding time.

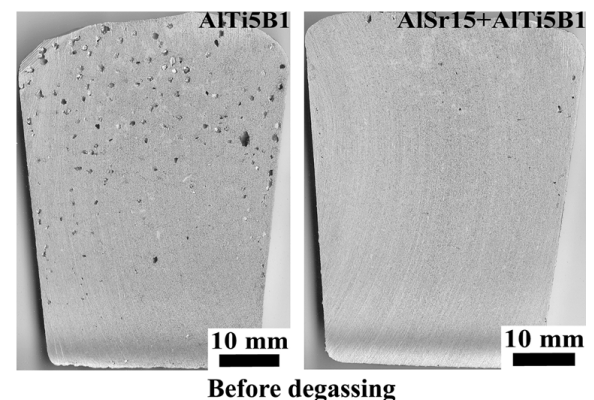

Before degassing

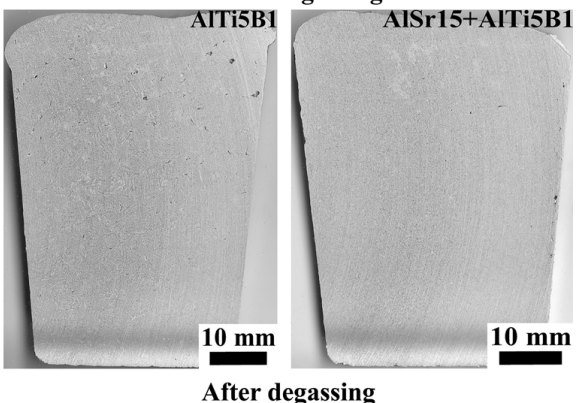

Figure 3. Cross section of RPT samples for AlTi5B1 and AlSr15 + AlTi5B1 additions after 10 min of holding time. 


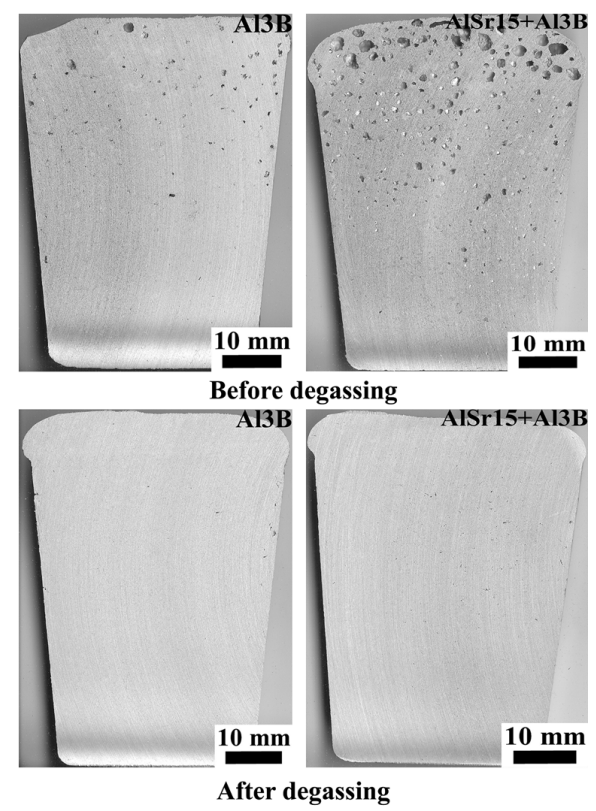

Figure 4. Cross section of RPT samples for Al3B and AlSr15 + Al3B additions after a 10 min hold.

RPT samples collected after a 30 min hold are shown in Figures 5-8. The alloy with AlSr15 addition has the highest porosity level in both the degassed and non-degassed melts. Non-treated alloy has the lowest level of porosity. It can be clearly seen that degassing reduces bifilms content significantly. These results are in agreement with the findings of Haberl et al. [35] and Lee et al. [45].

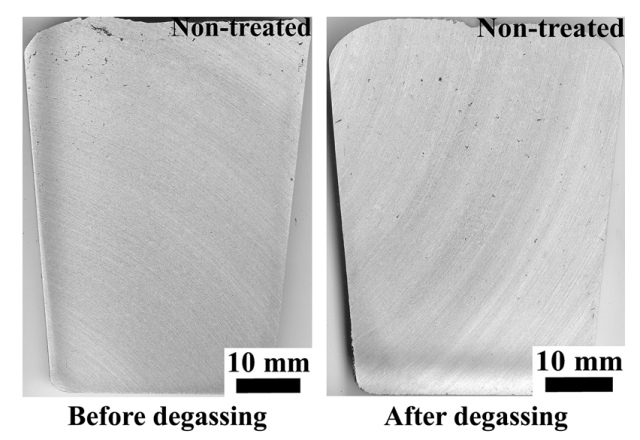

Figure 5. Cross section of RPT samples for non-treated alloy after $30 \mathrm{~min}$ of holding time.

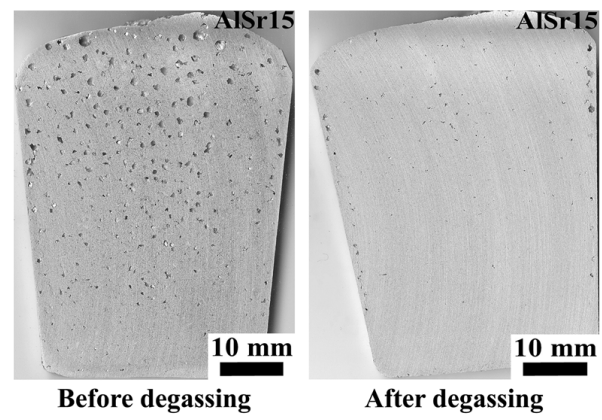

Figure 6. Cross section of RPT samples for AlSr15 addition after $30 \mathrm{~min}$ of holding time. 


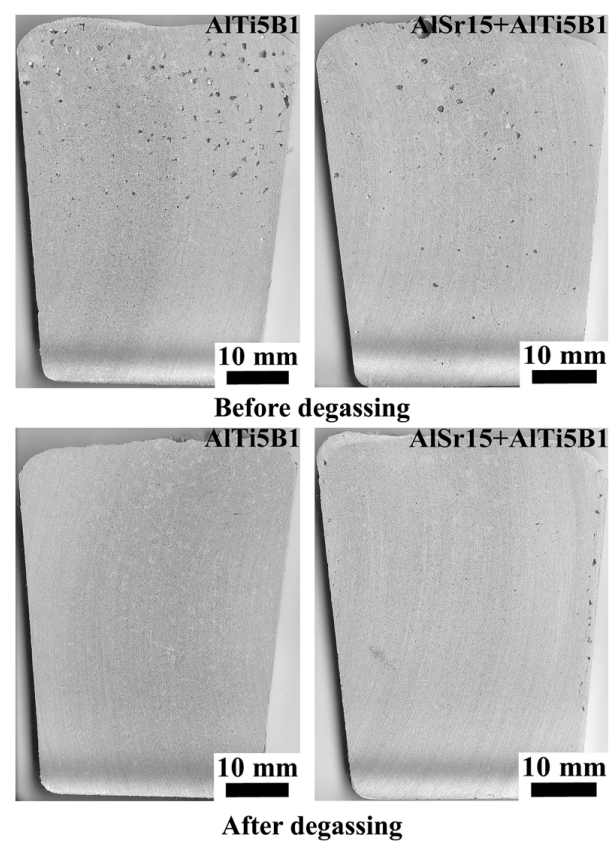

Figure 7. Cross section of RPT samples for AlTi5B1 and AlSr15 + AlTi5B1 additions, 30 min holding.

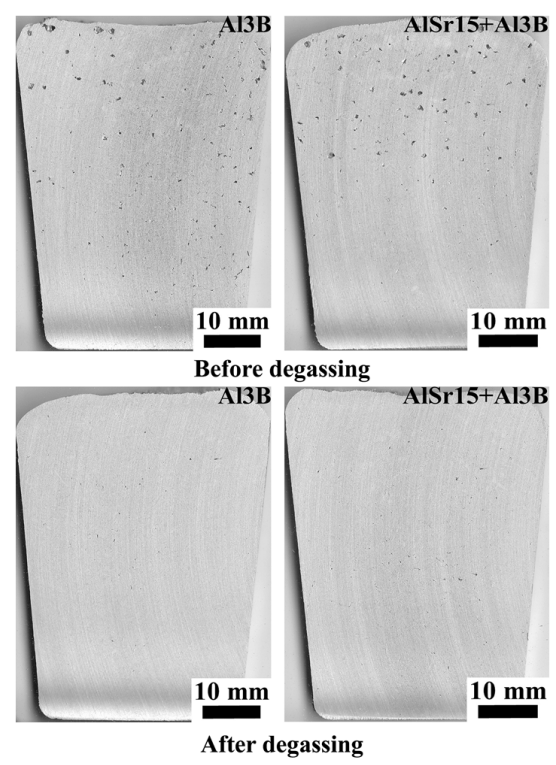

Figure 8. Cross section of RPT samples for Al3B and AlSr15 + Al3B additions after 30 min holding.

A comparison of cross section of RPT samples (Figures 1-8) can provide insights about the effect of holding time on porosity. It can be seen that number of pores increased slightly between 10 and $30 \mathrm{~min}$ of holding. For degassed melts, AlSr15 addition increased porosity slightly with increased holding time. However, other additions have almost the same number of pores for 10 and $30 \mathrm{~min}$ of holding times. Henceforth, AlSr15 addition seems to have introduced additional bifilms into the melt and resulted in formation of larger pores, which agrees with the results of previously reported studies [12,17-20,37,48-52]. Consequently, if the melt is not degassed after Sr addition, the melt should be held for 30 min for self-healing. Similar conclusions can be made for AlTi5B1 and AlSr15 + Al3B additions. When melts are degassed, it is not necessary to hold the melt longer than 10 min so that energy savings can be achieved. 
Although Iwahori et al. [25] speculated that Sr additions in the presence of bifilms increased the hydrogen content, there is an alternate explanation for the large increase in the number of pores with $\mathrm{Sr}$ additions. Liu et al. [14] found that $\mathrm{Sr}$ reacted with $\mathrm{Al}_{2} \mathrm{O}_{3}$ to form a mixed oxide, but its stoichiometry was not determined. One of the authors [53] determined that $\mathrm{Sr}$ additions lead to the formation of SrO. $\mathrm{Al}_{2} \mathrm{O}_{3}$ spinel, which can easily be fractured into smaller pieces through breakaway oxidation. This mechanism is in agreement with the results of Liu et al. [54] and provides an explanation on how the number of pores increased with Sr additions [55]. Yao et al. [56] had shown that in the presence of Sr, oxidation increased and nucleation of pores decreased.

Results of digital image processing were analyzed by using two different data: number density of pores $(N)$ and pore sizes. These two types of data are interpreted to be independent from each other; number density is a measure of how many heterogeneous nucleation sites were available during solidification. Pore sizes and their statistical distribution imply the driving force for the growth of pores, i.e., hydrogen content. These results are introduced and discussed separately.

\subsection{Number Density Measurements}

Number density data for all conditions as a function of holding time are presented in Figures 9-12. It is noteworthy that for the non-treated alloy, $N$ remains essentially constant with time for both treatments of the melt. This is a clear indication that melt is damaged when additions are made because the melt surface needs to be inevitably disturbed during the addition of grain refiner and/or modifying agents. Consequently, additional bifilms are created and entrained into the melt during these additions. Moreover, Sr additions result in an additional increase in the number of bifilms because Sr reacts with alumina to form a spinel which later fractures into smaller bifilms. These additional bifilms increase the number of pores that form later during solidification.
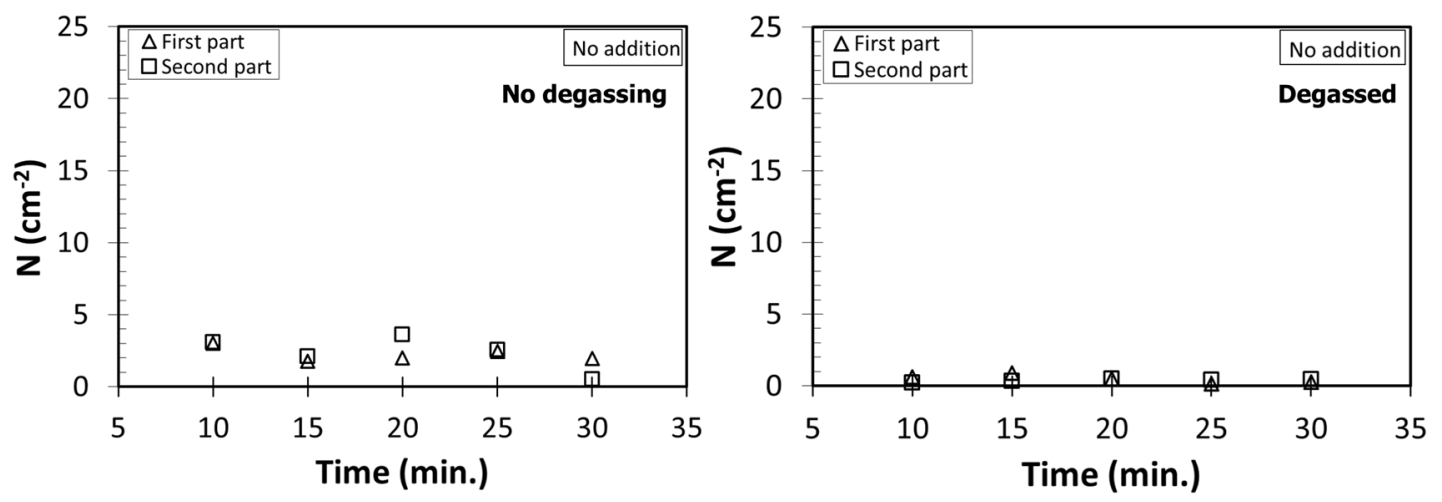

Figure 9. Change in number density for non-treated alloy with holding time.
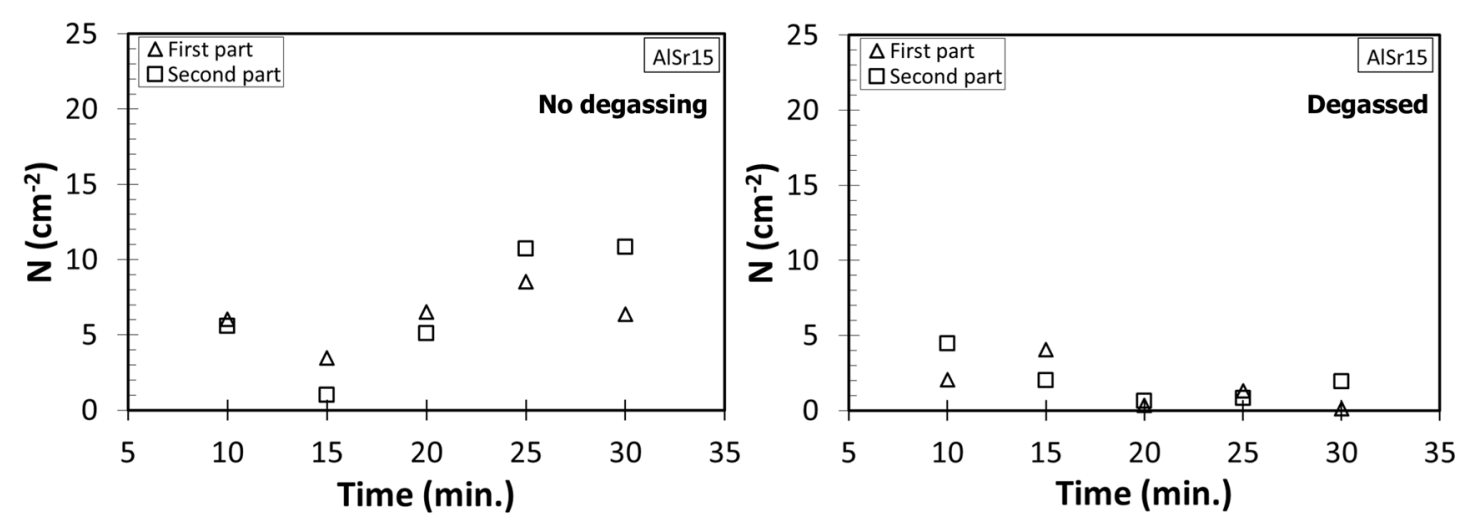

Figure 10. Change in number density for AlSr15 addition with holding time. 

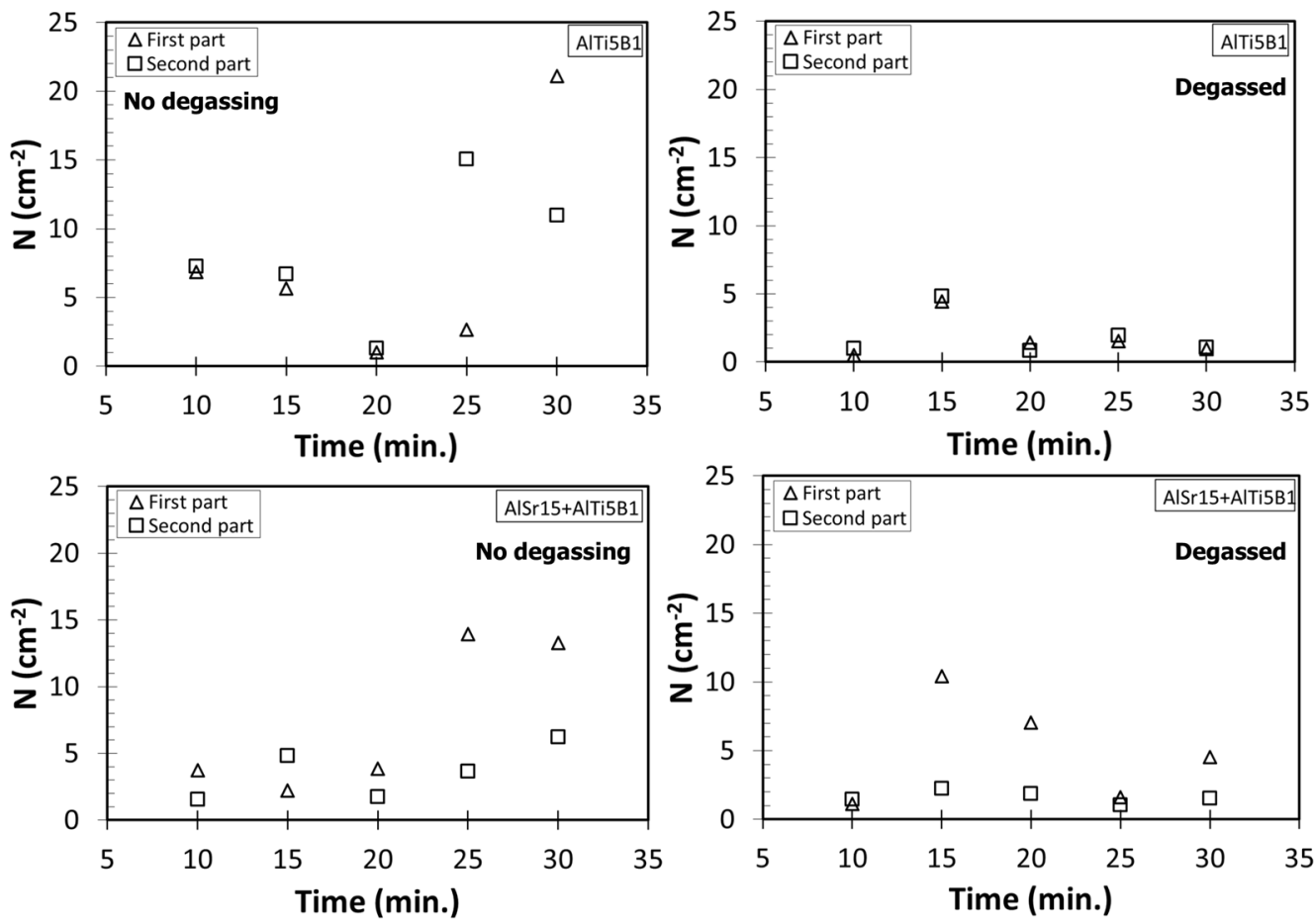

Figure 11. Change in number density for AlTi5B1 and AlSr15 + AlTi5B1 addition with holding time.
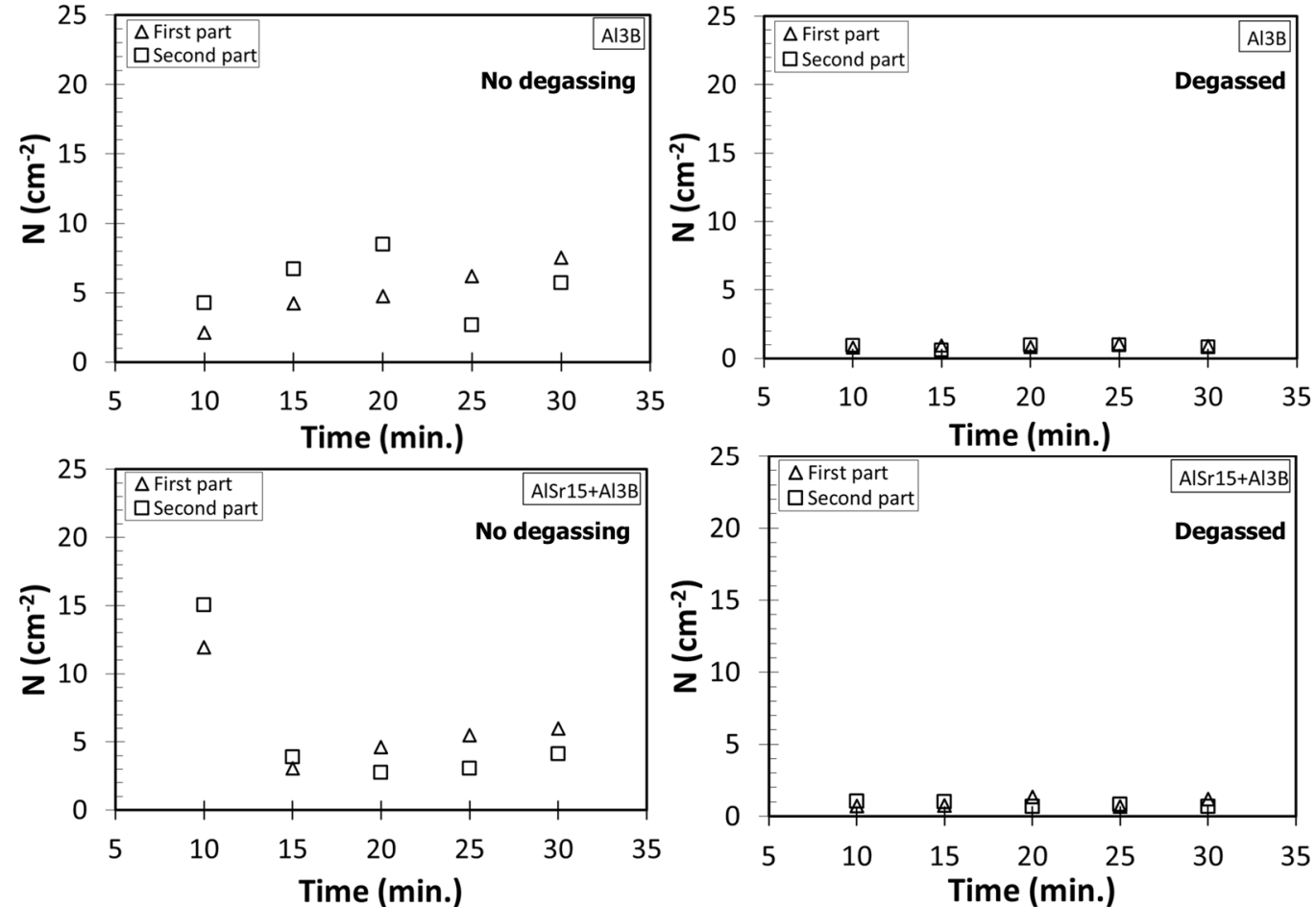

Figure 12. Change in number density for $\mathrm{Al} 3 \mathrm{~B}$ and $\mathrm{AlS} r 15+\mathrm{Al} 3 \mathrm{~B}$ addition with holding time.

For each condition, it is clear that degassing reduces the number density of defects (Figures 9-12) significantly, as discussed above. When all experimental conditions are considered, such as grain refining additions, modification and holding time, degassing is the only process that clearly improves the melt quality. Therefore, there is a strong evidence that melt quality can be improved by avoiding 
melt additions and effective degassing can remove existing bifilms by floatation. When melts that were not degassed are considered, Figures 9-12 show that each addition responds differently to holding time. For the AlSr15 addition, $N$ decreases until $15 \mathrm{~min}$ but then it starts to increase significantly with increased time. When AlSr15 is added into the melt along with AlTi5B1, N remains almost constant until $20 \mathrm{~min}$ of hold time and then increases significantly with time. It is also noteworthy that the increase of $\mathrm{N}$ is much more significant in the second samples. Hence variability is higher with increasing holding time as well. When Al3B and AlSr15 additions were made together, $N$ decreases until $15 \mathrm{~min}$ then it starts to increase again. The same behavior is observed in the AlSr15 addition condition. If AlTi5B1 is added without $\mathrm{Sr}, \mathrm{N}$ goes down until $20 \mathrm{~min}$ of holding time and then it starts to increase almost linearly with time.

For Al3B addition, the behavior of $N$ is quite complicated. $N$ increases until 20 min of holding time, but then it decreases until $25 \mathrm{~min}$ and then it increases again. Hence, the optimum holding time in non-degassed melts is determined by the type of melt addition; when there are no additions, there is no need to hold the melt for more than $10 \mathrm{~min}$. The same is true for AlSr15 + AlTi5B1 and Al3B additions as well. For AlSr15 and AlSr15 + Al3B additions, 15 min is the optimum holding time. For AlTi5B1 addition, the optimum holding time is found to be $20 \mathrm{~min}$.

For degassed melts, $N$ remains stable with time for the non-treated melt, Al3B and AlSr15 + Al3B conditions. When AlSr15 is added to the melt in degassed melts, $N$ decreases until 20 min then it starts to increase slightly. In degassed melts, the results for AlSr15 + AlTi5B1 addition are complicated, resembling those for Al3B addition in non-degassed melts where $N$ increases until 15 min then it goes down until $25 \mathrm{~min}$ and then it increases again. When AlTi5B1 added into the melt, $N$ increases until $15 \mathrm{~min}$ then it decreases.

\subsection{Size Distribution of Pores}

The size distribution of all pores was analyzed first by calculating the equivalent diameter, $d_{\mathrm{eq}}$, for all pores;

$$
d_{\mathrm{eq}}=2 \sqrt{\frac{A}{\pi}}
$$

where $A$ is the area of the pore on the polished surface of RPT sample's cross section. Subsequently, the pore size distribution for every condition was determined by assuming that $d_{\mathrm{eq}}$ follows the lognormal distribution, which is consistent with the theory that pore size distribution in castings should be lognormal [57]. Additionally, pore sizes in $\mathrm{Mg}$ [58] and $\mathrm{Al}$ [59] alloy castings were reported to follow the lognormal distribution. The density function $(f)$ for the lognormal distribution is written as;

$$
f\left(d_{\mathrm{eq}}\right)=\frac{1}{d_{\mathrm{eq}} \sigma \sqrt{2 \pi}} \exp \left[\frac{-\left(\ln \left(d_{\mathrm{eq}}\right)-\mu\right)^{2}}{2 \sigma^{2}}\right]
$$

where $\sigma$ is the shape and $\mu$ is the scale parameter. The expected value, i.e., mean of a lognormal distribution is found by;

$$
\bar{d}_{\mathrm{eq}}=e^{\mu+\sigma^{2} / 2}
$$

Parameters of the lognormal distribution were estimated by using the maximum likelihood method and the estimates for each condition are provided in Table 4. The goodness-of-fit of the estimated parameters was tested by using the Anderson-Darling statistic [60]. In all cases, the hypothesis that the data come from the fitted lognormal distributions could not be rejected. The fitted distributions for 10 and 30 min hold times for each condition are presented in Figures 13-16. 
Table 4. Estimated parameters of lognormal distribution of pore size.

\begin{tabular}{|c|c|c|c|c|c|}
\hline \multirow{2}{*}{ Degassing } & \multirow{2}{*}{ Additions } & \multicolumn{2}{|c|}{$\mu$} & \multicolumn{2}{|c|}{$\sigma$} \\
\hline & & $10 \mathrm{~min}$ & $30 \mathrm{~min}$ & $10 \mathrm{~min}$ & $30 \mathrm{~min}$ \\
\hline \multirow{6}{*}{ No Degassing } & No addition & 13.48 & 12.43 & 0.81 & 0.78 \\
\hline & AlSr15 & 13.08 & 11.96 & 0.71 & 1.02 \\
\hline & AlSr15 + AlTi5B1 & 11.97 & 11.30 & 0.90 & 0.69 \\
\hline & AlTi5B1 & 11.89 & 11.20 & 0.96 & 0.47 \\
\hline & Al3B & 11.98 & 11.52 & 0.93 & 0.82 \\
\hline & $\mathrm{AlSr} 15+\mathrm{Al} 3 \mathrm{~B}$ & 12.06 & 11.90 & 1.15 & 0.72 \\
\hline \multirow{6}{*}{ Degassed } & No addition & 12.59 & 12.67 & 0.73 & 0.79 \\
\hline & AlSr15 & 11.60 & 11.51 & 0.82 & 0.84 \\
\hline & AlSr15 + AlTi5B1 & 11.94 & 11.24 & 1.03 & 0.67 \\
\hline & AlTi5B1 & 11.79 & 11.56 & 0.93 & 1.32 \\
\hline & $\mathrm{Al} 3 \mathrm{~B}$ & 11.70 & 11.91 & 0.82 & 1.00 \\
\hline & $\mathrm{AlSr} 15+\mathrm{Al} 3 \mathrm{~B}$ & 11.46 & 11.62 & 0.70 & 0.84 \\
\hline
\end{tabular}
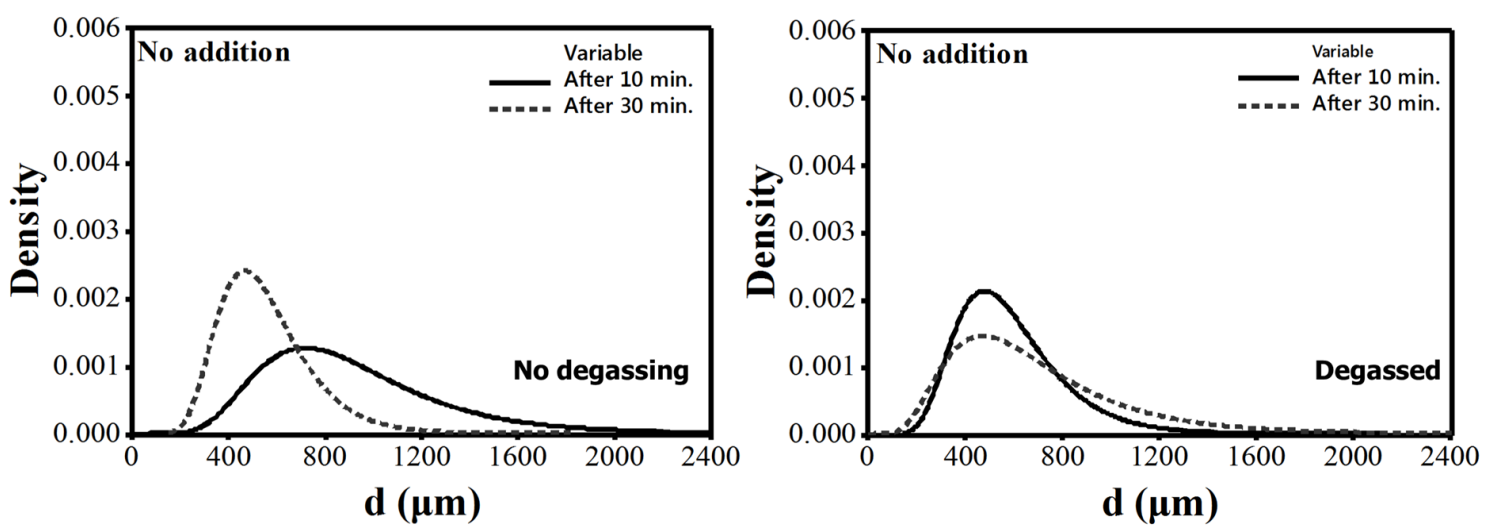

Figure 13. Lognormal distributions of pore sizes for non-treated alloy after 10 and 30 min holds.
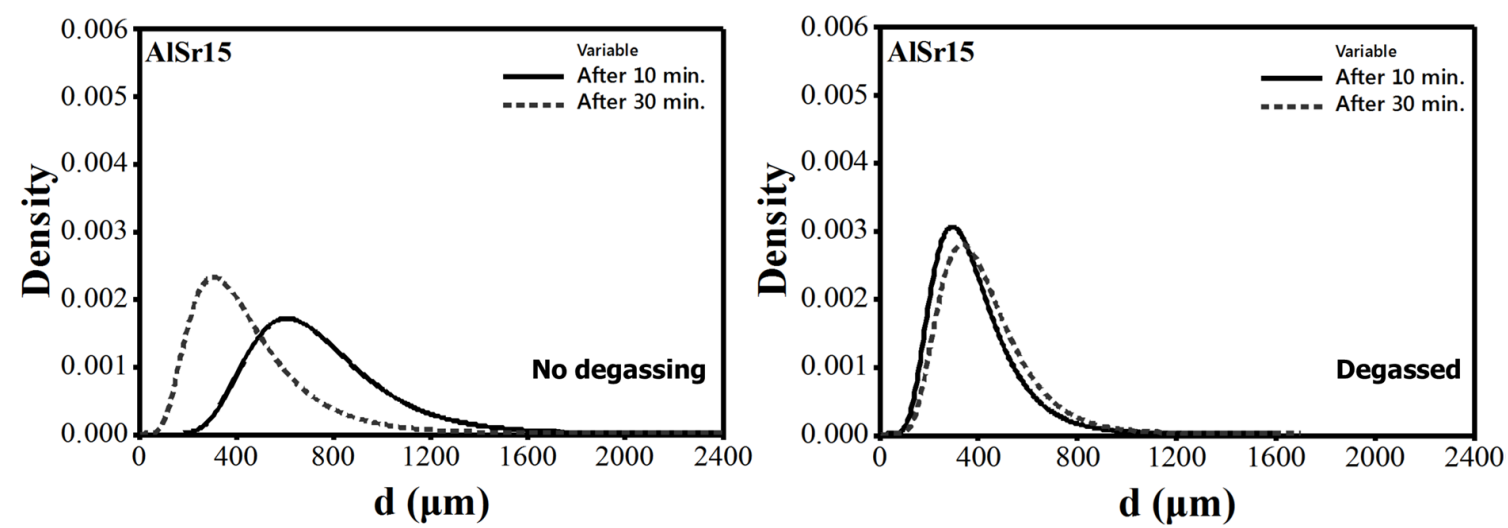

Figure 14. Lognormal distributions of pore sizes for AlSr15 addition after 10 and 30 min holds. 

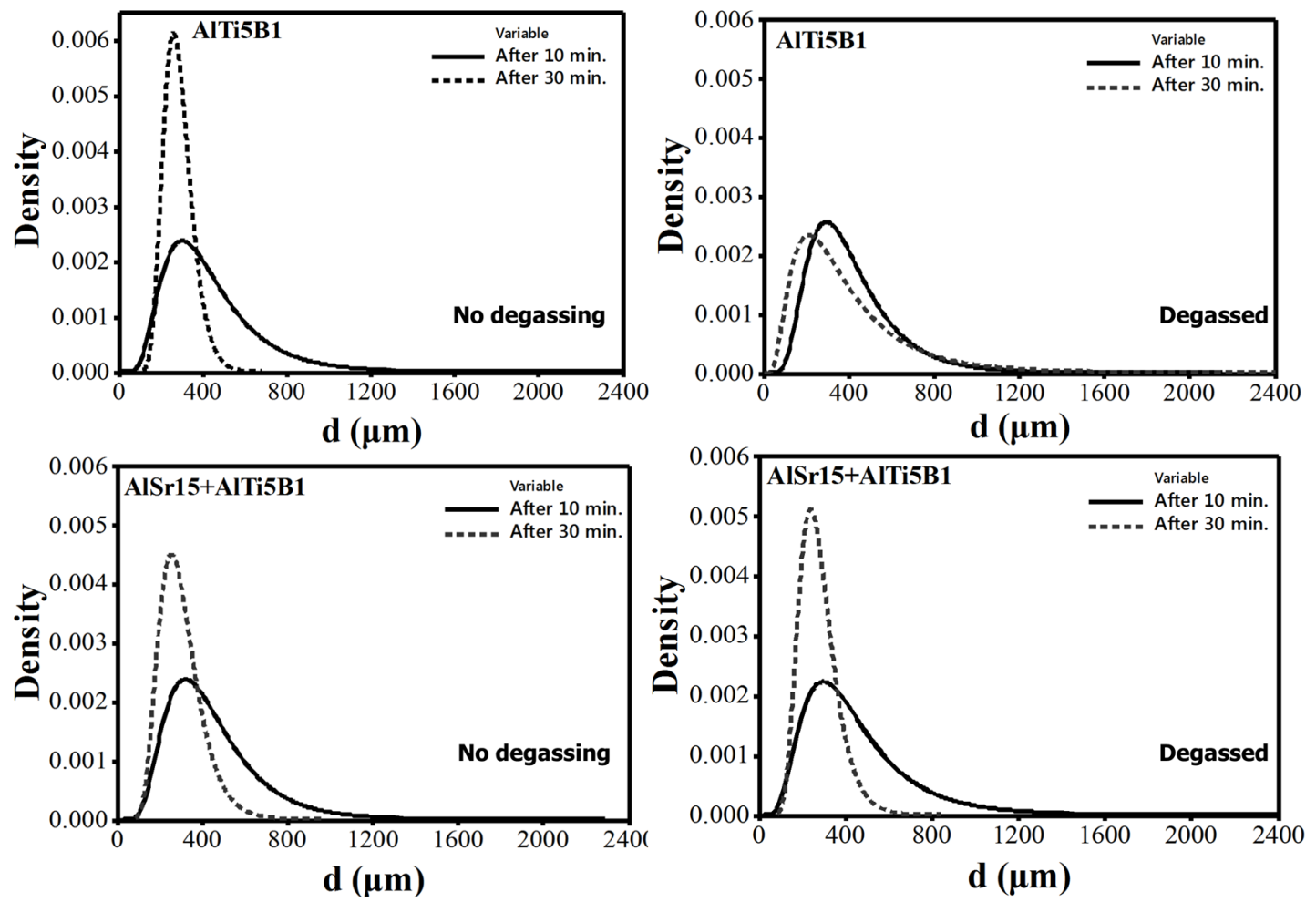

Figure 15. Lognormal distributions of pore sizes for AlTi5B1 and AlSr15 + AlTi5B1 addition after 10 and 30 min holds.
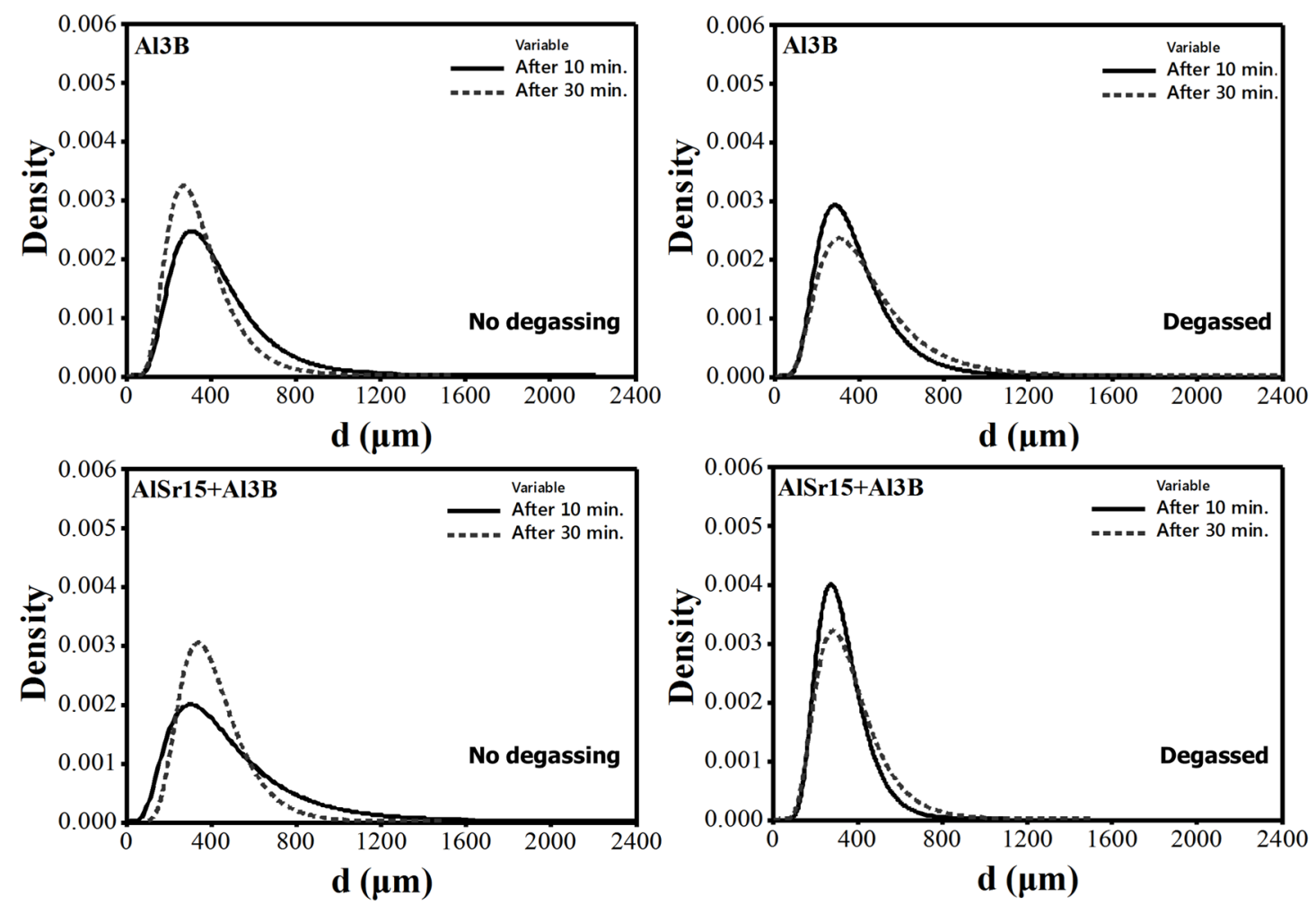

Figure 16. Lognormal distributions of pore sizes for Al3B and AlSr15 + Al3B addition after 10 and 30 min holds. 
For non-degassed melts, pore sizes get smaller with holding time for all conditions, as evidenced by the shift in the distribution to left with increasing times. Assuming that the size distribution of pores is controlled by hydrogen content of the melt, it can be concluded that natural degassing takes place with time in non-degassed melts. Degassed melts, however, do not benefit from holding time to decrease the size of their pores, with the only exception of the "AlSr15 + AlTi5B1" condition, which behaves like the non-degassed melts. Because degassing, in most cases, has reduced the hydrogen content to such low levels that natural degassing with time barely occurs.

The anomalous behavior of degassed melts with the "AlSr15 + AlTi5B1" addition can be explained by the formation $\mathrm{SrO}_{\mathrm{Al}} \mathrm{Al}_{2} \mathrm{O}_{3}$ spinel and its fracture to smaller pieces, as explained above. Campbell [44] stated that Ti nucleates heterogeneously on bifilms and causes them to sediment to the bottom of the crucible. Hence, the combined Sr-Ti addition results in smaller bifilms, fractured due to Sr, to sediment more effectively after the nucleation of Ti on them.

The summary of mean number density and mean pore diameter, calculated by using Equation (3) and estimated parameters in Table 4, after hold times of 10 and $30 \mathrm{~min}$ is presented in Table 5.

Table 5. Summary of mean number density and mean pore diameter after 10 and 30 min holds.

\begin{tabular}{|c|c|c|c|c|c|}
\hline \multirow{2}{*}{ Degassing } & \multirow{2}{*}{ Additions } & \multicolumn{2}{|c|}{$\bar{N}\left(\mathrm{~cm}^{-2}\right)$} & \multicolumn{2}{|c|}{$\bar{d}(\mu \mathrm{m})$} \\
\hline & & $10 \mathrm{~min}$ & $30 \mathrm{~min}$ & $10 \mathrm{~min}$ & $30 \mathrm{~min}$ \\
\hline \multirow{6}{*}{ No Degassing } & No addition & 6.10 & 2.48 & 917 & 544 \\
\hline & AlSr15 & 11.62 & 17.19 & 739 & 454 \\
\hline & AlSr15 + AlTi5B1 & 5.30 & 19.51 & 440 & 301 \\
\hline & AlTi5B1 & 14.13 & 32.06 & 432 & 278 \\
\hline & $\mathrm{Al} 3 \mathrm{~B}$ & 6.40 & 13.23 & 451 & 346 \\
\hline & $\mathrm{AlSr} 15$ + Al3B & 26.96 & 10.09 & 490 & 409 \\
\hline \multirow{6}{*}{ Degassed } & No addition & 0.86 & 0.75 & 579 & 645 \\
\hline & AlSr15 & 6.51 & 2.04 & 361 & 349 \\
\hline & AlSr15 + AlTi5B1 & 2.59 & 6.04 & 449 & 295 \\
\hline & AlTi5B1 & 1.49 & 2.00 & 406 & 402 \\
\hline & $\mathrm{Al} 3 \mathrm{~B}$ & 1.73 & 1.73 & 388 & 438 \\
\hline & $\mathrm{AlSr} 15+\mathrm{Al} 3 \mathrm{~B}$ & 1.77 & 1.84 & 328 & 365 \\
\hline
\end{tabular}

Mean number density and mean pore diameter values in Table 5 provide new insights, in addition to those stated previously:

1. In non-degassed castings, $N$ before $S r$ addition can be taken as $6.10 \mathrm{~cm}^{-2}$, the value for "no addition" in Table 5. After Sr addition, $N$ is almost doubled to $11.62 \mathrm{~cm}^{-2}$. Almost the same magnitude of increase takes place in degassed melts, from 0.86 to $6.51 \mathrm{~cm}^{-2}$, after the addition of Sr. This increase is of course due to entrainment of new surface oxides, as stated by Campbell [5], and at least partially due to the reaction of $\mathrm{Sr}$ with $\mathrm{Al}_{2} \mathrm{O}_{3}$ oxide, as suggested Liu et al. [57].

2. That $\mathrm{Sr}$ addition increases mean pore diameter in non-degassed melts but has essentially no effect in degassed melts are in agreement with the findings of Iwahori et al. [26]. When $N$ is low, mean pore diameter does not change with hold time either, resulting in a stable melt quality.

3. In non-degassed "no addition" melts, there is evidence for natural degassing (lower mean pore diameter) and floatation of bifilms to the surface of melt (lower $N$ ) with time.

4. The strong increase in $N$ with time with Ti additions in non-degassed as well as degassed melts can be interpreted as sedimentation of bifilms to the bottom of the ladle with holding time, as a result of Ti nucleating heterogeneously on bifilms. Because $\mathrm{Ti}$ is heavier than $\mathrm{Al}$, these phases help bifilms sink to the bottom.

5. The increase in $N$ with holding time for $\mathrm{Sr}$ and $\mathrm{B}$ additions cannot be completely explained by sedimentation because these two elements have slightly lower density than Al. Therefore, additional research is needed to uncover the reasons for this finding. 
6. The absolute best melt quality (lowest $N$ ) is obtained when the melt is degassed and no addition is made. Moreover, there is virtually no change in $N$ with holding time, although there is a decrease in mean pore diameter, due to natural degassing. Therefore, to save energy, it is sufficient to only have an effective degassing operation to clean $\mathrm{Al}-7 \% \mathrm{Si}-\mathrm{Mg}$ melts.

\section{Conclusions}

- The absolute best melt quality is obtained when the melt is degassed and no addition is made. Therefore, degassing operation can undoubtedly clean $\mathrm{Al}-7 \% \mathrm{Si}-\mathrm{Mg}$ melts.

- Comparing the degassing operation, non-treated alloy has the lowest levels of number density of defects, compared to other additions. It is concluded that all melt additions degrade melt quality.

- There is an evidence that natural degassing occurs where bifilms float to the surface of melt with time.

- Bifilms sediment to the bottom of the ladle with holding time when Ti is added to the melt. This reveals that Ti is heterogeneously nucleates on bifilms.

- Sr additions to A356 increased the number of bifilms in the melt and also resulted larger pores. Sr reacts with $\mathrm{Al}_{2} \mathrm{O}_{3}$ to form $\mathrm{SrO} . \mathrm{Al}_{2} \mathrm{O}_{3}$ spinel, which results in fracturing of oxides into smaller pieces through breakaway oxidation.

- The increase in $\mathrm{N}$ with holding time for $\mathrm{Sr}$ and B additions cannot be completely explained by sedimentation because these two elements have slightly lower density than Al. Therefore, additional research is needed to uncover the reasons for this finding.

Acknowledgments: This work has been supported by the Scientific Research Projects Coordination Unit of Selcuk University (Project number: 13101026). Author would like to thank TUBITAK (Turkey) for its supporting.

Author Contributions: M.U. performed the experiments for his doctoral thesis with D.D., who designed the experiments and also served as the first supervisor. R.C. is the co-supervisor. MT is the supervisor during which M.U. carried out a 1 year project in UNF by the support of TUBITAK. M.T. and M.U. analyzed the data and interpreted the results.

Conflicts of Interest: The authors declare no conflict of interest.

\section{References}

1. Campbell, J. Complete Casting Handbook: Metal Casting Processes, Metallurgy, Techniques and Design; Elsevier Science: Oxford, UK, 2011; p. 3.

2. Anson, J.; Gruzleski, J. The quantitative discrimination between shrinkage and gas microporosity in cast aluminum alloys using spatial data analysis. Mater. Charact. 1999, 43, 319-335. [CrossRef]

3. Brandt, F.; Bishop, H.; Pellini, W. Solidification at corner and core positions. AFS Trans. 1953, 61, 451.

4. Campbell, J. Cast Met. Res. J. 1969, 4, 1.

5. Campbell, J. Entrainment defects. Mater. Sci. Technol. 2006, 22, 127-145. [CrossRef]

6. Dispinar, D.; Akhtar, S.; Nordmark, A.; di Sabatino, M.; Arnberg, L. Degassing, hydrogen and porosity phenomena in A356. Mater. Sci. Eng. A 2010, 527, 3719-3725. [CrossRef]

7. Dispinar, D.; Campbell, J. Critical assessment of reduced pressure test. Part 2: Quantification. Int. J. Cast Met. Res. 2004, 17, 287-294. [CrossRef]

8. Dispinar, D.; Campbell, J. Use of bifilm index as an assessment of liquid metal quality. Int. J. Cast Met. Res. 2006, 19, 5-17. [CrossRef]

9. Dispinar, D.; Campbell, J. Effect of casting conditions on aluminium metal quality. J. Mater. Process. Technol. 2007, 182, 405-410. [CrossRef]

10. Dispinar, D.; Campbell, J. Porosity, hydrogen and bifilm content in Al alloy castings. Mater. Sci. Eng. A 2011, 528, 3860-3865. [CrossRef]

11. Dong, X.; He, L.; Huang, X.; Li, P. Effect of electromagnetic transport process on the improvement of hydrogen porosity defect in A380 aluminum alloy. Int. J. Hydrog. Energy 2015, 40, 9287-9297. [CrossRef]

12. Drouzy, M.; Jacob, S.; Richard, M. Interpretation of Tensile Results by Means of Quality Index And Probable Yield Strength-Application to Al-Si7 Mg Foundry Alloys-France. Int. Cast Met. J. 1980, 5, 43-50. 
13. El-Sayed, M.; Hassanin, H.; Essa, K. Effect of casting practice on the reliability of Al cast alloys. Int. J. Cast Met. Res. 2016, 29, 350-354. [CrossRef]

14. Liu, S.-G.; Cao, F.-Y.; Zhao, X.-Y.; Jia, Y.-D.; Ning, Z.-L.; Sun, J.-F. Characteristics of mold filling and entrainment of oxide film in low pressure casting of A356 alloy. Mater. Sci. Eng. A 2015, 626, 159-164. [CrossRef]

15. Mutwil, J. An establish attempt of reasons of machining splinter formation in AC44200 alloy high pressure die castings. Arch. Foundry Eng. 2008, 8, 159-166.

16. Zeng, J.; Li, D.; Kang, M.; He, H.; Hu, Z. Nanostructure of Aluminum Oxide Inclusion and Formation of Hydrogen Bubbles in Molten Aluminum. J. Nanosci. Nanotechnol. 2013, 13, 6948-6952. [CrossRef] [PubMed]

17. Gruzleski, J.E.; Closset, B.M. The Treatment of Liquid Aluminum-Silicon Alloys; American Foundrymen's Society, Inc.: Des Plaines, IL, USA, 1990; pp. 25-55.

18. Harris, R.; Lipson, S.; Rosenthal, H. Tensile properties of aluminum-silicon magnesium alloys and the effect of sodium modification. AFS Trans. 1956, 64, 470-481.

19. Shivkumar, S.; Ricci, S., Jr.; Steenhoff, B.; Apelian, D.; Sigworth, G. An experimental study to optimize the heat treatment of A356 alloy. AFS Trans. 1989, 97, 791-810.

20. Fang, Q.; Granger, D. Porosity formation in modified and unmodified A356 alloy castings. AFS Trans. 1989, 97, 989-1000.

21. Brosnan, M.; Shivkumar, S. Elevated-temperature tensile properties and fracture behavior of A 356 castings. Am. Foundrym. Soc. Inc. 1996, 727-737.

22. Byczynski, G.; Cusinato, D. The effects of strontium and grain refiner additions on the fatigue and tensile properties of industrial Al-Si-Cu-Mg alloy castings produced using the Ford Motor Company-Cosworth precision sand process. Int. J. Cast Met. Res. 2002, 14, 315-324. [CrossRef]

23. Gundlach, R.; Ross, B.; Hetke, A.; Valtierra, S.; Mojica, J. Thermal Fatigue Resistance of Hypoeutectic Aluminum-Silicon Casting Alloys (94-141). Trans. Am. Foundrym. Soc. Inc. 1994, 102, 205-224.

24. Campbell, J.; Tiryakioğlu, M. Review of effect of P and Sr on modification and porosity development in Al-Si alloys. Mater. Sci. Technol. 2010, 26, 262-268. [CrossRef]

25. Iwahori, H.; Yonekura, K.; Yamamoto, Y.; Nakamura, M. Occurring Behavior of Porosity and Feeding Capabilities of Sodium-and Strontium-Modified Al-Si Alloys. AFS Trans. 1990, 98, 167-173.

26. Gruzleski, J.; Handiak, N.; Campbell, H.; Closset, B. Hydrogen measurement by Telegas in strontium treated A365 Metals. AFS Trans. 1986, 28, 147-154.

27. Argo, D.; Gruzleski, J. Porosity in modified aluminum alloy castings. AFS Trans. 1988, 96, 65-74.

28. Dinnis, C.; Dahle, A.; Taylor, J.; Otte, M. The influence of strontium on porosity formation in Al-Si alloys. Metall. Mater. Trans. A 2004, 35, 3531-3541. [CrossRef]

29. Tiedje, N.S.; Taylor, J.A.; Easton, M.A. Feeding and distribution of porosity in cast Al-Si alloys as function of alloy composition and modification. Metall. Mater. Trans. A 2012, 43, 4846-4858. [CrossRef]

30. Tiedje, N.S.; Taylor, J.A.; Easton, M.A. A new multi-zone model for porosity distribution in Al-Si alloy castings. Acta Mater. 2013, 61, 3037-3049. [CrossRef]

31. Liao, H.; Wu, Y.; Fan, R.; Wang, Q. Effect of Sr content on porosity formation in directionally solidified Al-12.3 wt.\% Si alloy. China Foundry 2014, 11, 435-439.

32. Roy, N.; Zhang, L.; Louchez, P.; Samuel, F. Porosity formation in Al-9 wt \% Si-3 wt \% Cu-X alloy systems: Measurements of porosity. J. Mater. Sci. 1996, 31, 1243-1254. [CrossRef]

33. Farhoodi, B.; Raiszadeh, R.; Ghanaatian, M.-H. Role of double oxide film defects in the formation of gas porosity in commercial purity and Sr-containing Al alloys. J. Mater. Sci. Technol. 2014, 30, 154-162. [CrossRef]

34. El-Sayed, M.A.; Salem, H.A.; Kandeil, A.Y.; Griffiths, W. Effect of holding time before solidification on double-oxide film defects and mechanical properties of aluminum alloys. Metall. Mater. Trans. B 2011, 42, 1104-1109. [CrossRef]

35. Haberl, K.; Schumacher, P.; Geier, G.; Stauder, B. Characterization of the melt quality and impurity content of an LM25 alloy. Metall. Mater. Trans. B 2009, 40, 812. [CrossRef]

36. Kori, S.; Murty, B.; Chakraborty, M. Development of an efficient grain refiner for Al-7Si alloy and its modification with strontium. Mater. Sci. Eng. A 2000, 283, 94-104. [CrossRef]

37. Yuan, L.; Chao, D.; Li, Y.-X. Grain refining mechanism of Al-3B master alloy on hypoeutectic Al-Si alloys. Trans. Nonferr. Met. Soc. China 2011, 21, 1435-1440. 
38. Dispinar, D.; Nordmark, A.; Voje, J.; Arnberg, L. Influence of Hydrogen Content And Bi-Film Index on Feeding Behaviour of Al-7Si. In Proceedings of the 138th TMS Annual Meeting, Shape Casting: 3rd International Symposium, San Francisco, CA, USA, 15-19 February 2009; pp. 63-70.

39. Arnberg, L.; Bäckerud, L.; Klang, H. 1: Production and properties of master alloys of Al-Ti-B type and their ability to grain refine aluminium. Met. Technol. 1982, 9, 1-6. [CrossRef]

40. Schaffer, P.L.; Dahle, A.K. Settling behaviour of different grain refiners in aluminium. Mater. Sci. Eng. A 2005, 413, 373-378. [CrossRef]

41. Anyalebechi, P.N. Hydrogen-induced gas porosity formation in $\mathrm{Al}-4.5 \mathrm{wt} \% \mathrm{Cu}-1.4 \mathrm{wt} \% \mathrm{Mg}$ alloy. J. Mater. Sci. 2013, 48, 5342-5353. [CrossRef]

42. Fakhraei, O.; Emamy, M.; Farhangi, H. The effect of Al-5Ti-1B grain refiner on the structure and tensile properties of Al-20\% Mg alloy. Mater. Sci. Eng. A 2013, 560, 148-153. [CrossRef]

43. Lee, J.-M.; Lee, S.-H.; Yoon, J.-H.; Kim, K.-H. Effects of Melt Treatments on Microstructures and Mechanical Properties of A357 Alloy. J. Korea Foundry Soc. 2003, 23, 69-76.

44. Eskin, D.; Alba-Baena, N.; Pabel, T.; da Silva, M. Ultrasonic degassing of aluminium alloys: Basic studies and practical implementation. Mater. Sci. Technol. 2015, 31, 79-84. [CrossRef]

45. Lee, C.; So, T.; Shin, K. Effect of Gas Bubbling Filtration Treatment on Microporosity Variation in A356 Aluminium Alloy. Acta Metall. Sin. 2016, 29, 638-646. [CrossRef]

46. Puga, H.; Barbosa, J.; Seabra, E.; Ribeiro, S.; Prokic, M. The influence of processing parameters on the ultrasonic degassing of molten AlSi9Cu3 aluminium alloy. Mater. Lett. 2009, 63, 806-808. [CrossRef]

47. Dispinar, D.; Campbell, J. Reduced Pressure Test (RPT) for Bifilm Assessment. In Proceedings of the Shape Casting: 5th International Symposium, San Diego, CA, USA, 16-20 February 2014; pp. 243-251.

48. Akhtar, S.; Arnberg, L.; di Sabatino, M.; Dispinar, D.; Syvertsen, M. A comparative study of porosity and pore morphology in a directionally solidified A356 alloy. Int. J. Metalcast. 2009, 3, 39-52. [CrossRef]

49. Akhtar, S.; Dispinar, D.; Arnberg, L.; di Sabatino, M. Effect of hydrogen content, melt cleanliness and solidification conditions on tensile properties of A356 alloy. Int. J. Cast Met. Res. 2009, 22, 22-25. [CrossRef]

50. Çolak, M.; Kayikci, R.; Dispinar, D. Melt Cleanliness Comparison of Chlorine Fluxing and Ar Degassing of Secondary Al-4Cu. Metall. Mater. Trans. B 2016, 47, 2705-2709. [CrossRef]

51. Koca, E.; Yuksel, C.; Erzi, E.; Dişpınar, D. Quality Assessment of A356 Ingots from Different Suppliers in Wheel Production. In Proceedings of the Shape Casting: 6th International Symposium, Nashville, TN, USA, 14-18 February 2016; pp. 77-83.

52. Ludwig, T.; di Sabatino, M.; Arnberg, L.; Dispinar, D. Influence of oxide additions on the porosity development and mechanical properties of A356 aluminium alloy castings. Int. J. Metalcast. 2012, 6, 41-50. [CrossRef]

53. Dispinar, D.; Istanbul University, Istanbul, Turkey. Unpublished research, 2017.

54. Liu, L.; Samuel, A.; Samuel, F.; Doty, H.; Valtierra, S. Influence of oxides on porosity formation in Sr-treated Al-Si casting alloys. J. Mater. Sci. 2003, 38, 1255-1267. [CrossRef]

55. Nateghian, M.; Raiszadeh, R.; Doostmohammadi, H. Behavior of Double-Oxide Film Defects in Al-0.05 wt pct Sr Alloy. Metall. Mater. Trans. B 2012, 43, 1540-1549. [CrossRef]

56. Yao, L.; Cockcroft, S.; Reilly, C.; Zhu, J. Factors affecting the nucleation kinetics of microporosity formation in aluminum alloy A356. Metall. Mater. Trans. A 2012, 43, 1004-1016. [CrossRef]

57. Dvorak, H.; Schwegtier, E. Statistical distribution of flaw sizes. Int. J. Fract. Mech. 1972, 8, 110-111. [CrossRef]

58. Tiryakioğlu, M. Pore size distributions in AM50 Mg alloy die castings. Mater. Sci. Eng. A 2007, 465, $287-289$. [CrossRef]

59. Tiryakioğlu, M. On fatigue life variability in cast Al-10\% Si-Mg alloys. Mater. Sci. Eng. A 2010, 527, 1560-1564. [CrossRef]

60. Anderson, T.W.; Darling, D.A. A test of goodness of fit. J. Am. Stat. Assoc. 1954, 49, 765-769. [CrossRef]

(C) 2017 by the authors. Licensee MDPI, Basel, Switzerland. This article is an open access article distributed under the terms and conditions of the Creative Commons Attribution (CC BY) license (http:/ / creativecommons.org/licenses/by/4.0/). 